Article Review

\title{
Manfaat dan Kandungan Gizi Bulu Babi (Echinoidea) di Indonesia
}

\author{
Penska Rukmana* \\ *Jurusan Manajemen Sumber Daya Perairan, Fakultas Perikanan dan IImu Kelautan \\ Universitas Negeri Gorontalo. Email: penskarukmana571@gmail.com
}

\section{Introduction}

Indonesia merupakan negara kepulauan, yang memiliki kekayaan alam, flora dan fauna yang sangat tinggi yang menyediakan sumberdaya alam khususnya di ekosistem pesisir dan laut yang menjadi sumber kehidupan, pangan, tambang mineral, kawasan rekreasi atau pariwisata (Bengen, 2000 dalam Yudasmara, 2013). Dan pantai menjadi wiayah pembatas daratan dan lautan. Bulu babi pun salah satu keanekaragaman yang ada di pantai (Wulandewi dkk., 2015). Salah satu potensi sumber daya perikanan yang mempunyai manfaat ekonomi bagi kehidupan manusia adalah bulu babi (Nane, 2019a)

Azizi, (1987) dalam Laning dkk., (2014) menyatakan bahwa bulu babi (Echinoidea) terbagi dalam dua subkelas berdasarkan bentuk tubuhnya, yaitu bulu babi beraturan (regular sea urchin) dan bulu babi tidak beraturan (irregular sea urchin). Produk bulu babi baik telur ataupun gonadnya sangat digemari oleh masyarakat jepang dan Wakatobi (Nane, 2019d). Harga jualnya yang mahal, dan rasa telur bulu babi lembut dan lezat, juga mempunyai nilai gizi yang tinggi (Zakaria, 2013; Nane, 2019c). Bulu babi dalam kelompok iregular memiliki bentuk tubuh hemisfer, membulat dibagian atas dan merata dibagian bawah, juga memiliki duri yang panjang dan kadang warnanya menyolok. Sedangkan kelompok irregular memiliki bentuk tubuh yang memipih (Basir, 2014), Bulu babi merupakan organisme yang tergolong dalam kelas Echinoidea dan dapat dimanfaatkan sebagai sumber pangan bergizi. Bulu babi juga dapat dijadikan sebagai hiasan dan juga berguna dibidang kesehatan guna untuk pengobatan penyakit (Angka dan Suhartono, 
2000 dalam Nasrullah dkk., 2018). Untuk menggerakkan tubuhnya bulu babi menggunakan duri dan kaki tabung, selain itu duri dianggap sebagai pelindung tubuhnya (Silvina, 2017).

Bulu babi atau yang dikenal dengan sea urchin ini pernyebarannya hampir terlihat di seluruh perairan. Menurut Suwignyo et al. (2005) dalam Prasetyo dkk., (2019) menyatakan bahwa bulu babi yang tersebar diseluruh dunia terdapat 950 jenis, dan diantaranya perairan Indonesia terdapat 84 jenis yang berasal dari 48 ordo dan 21 famili (Aziz, 1993 dalam Prasetyo dkk., 2019). Organisme ini menghasilkan toksin yang bisa dijadikan sebagai pengobatan dan juga antibiotik yang mengandung senyawa bioaktif (Abubakar et al., 2012 dalam Akerina dkk., 2015). Adapun hubungan makroalgae dengan bulu babi, yaitu jika berkurangnya bulu babi maka akan meningkatkan nutrien yang mengakibatkan kelimpahan makroalge (blooming) dan tentunya akan memberikan dampak negatif terhadap kehidupan karang (Miala dkk., 2015). Salah satu penyebab utama berkurangnya bulu babi adalah overfishing (Nane, 2019b)

Umumnya bentuk bulu babi (Echinoidea) menyerupai bola, memiliki sisi tubuh segi lima (simetris radial) dengan cangkang keras dan berkapur dan dipenuhi dengan duri serta tidak berlengan (Kuncoro, 2004 dalam Arhas dkk., 2015). Tubuhnya terdiri dari tiga bagian, yaitu: duburnya menghadap ke atas (aboral) puncak bulatan cangkang, sedangkan mulut terletak di bagian oral menghadap ke dasar laut. Interambulakral (tidak terdapat kaki tabung) berada diantara sistem apikal dan sistem peristomial dan lempeng-lempeng ambulakral (penjuluran kaki tabung). Dan di bagian tengah sisi aboral terdapat sistem apikal dan pada bagian tengah sisi oral terdapat sistem peristomial. (Sugiarto, 1995 dalam Arhas dkk., 2015).

Salah satu habitat bagi bulu babi adalah padang lamun (Nane, 2019d). Kehadiran berbagai biota yang berasosiasi dengan ekosistem padang lamun termasuk bulu babi yaitu untuk mencari makan, tempat hidup, memijah dan tempat berlindung untuk menghindari predator tergantung pada tingginya tutupan vegetasi lamun diperairan (Supono dan Arbi, 2010 dalam Firmandana dkk., 2014). Adapun faktor lingkungan yang memengaruhi keberadaan bulubabi diantaranya adalah salinitas, suhu, dn kedalaman. Sedikitnya populasi bulu babi akan 
berdampak buruk bagi lingkungan (Julian dkk., 2017). Tidak semua bulu babi di perairan hidup mengelompok, mereka hidup mengelompok tergantung jenis habitatnya. Bulu babi yang cenderung hidup mengelompok adalah jenis Diadema setosum, Tripneustes gratilla, D. antillarum, Lytechinus variegatus, Temnopleurus toreumaticus, T. ventricosus dan Strongylocentrotus spp., sedangkan yang cenderung hidup menyendiri adalah bulu babi jenis Echinothrix diadema, Toxopneustes pileolus, Mespilia globulus dan Pseudoboletia maculata (Aziz, 1994: 36 dalam Lubis dkk., 2017).

Bukan hanya padang lamun tetapi ekosistem terumbu karang merupakan salah satu tempat berasosiasinya bulu babi, karena bulu babi termasuk ke dalam filum echinodermata yang tersebar dari daerah intertidal dangkal hingga ke laut dalam. Menurut Nystrom et al., (2000) dalam Purwandatama dkk., (2014), Bagi komunitas terumbu karang bulu babi merupakan salah satu spesies kunci (keystone species) (Nystrom et al., 2000 dalam Purwandatama dkk., 2014). Genus Diadema merupakan salah satu jenis bulu babi yang biasanya terdapat di ekosistem terumbu karang (Nane dkk., 2020), Menurut Sugiarto dan Supardi (1995) dalam Purwandatama dkk., (2014) bahwa pada lingkungan berbeda jenis ini genus Diadema dianggap sebagai omnivora yang dapat beradaptasi dengan memakan polip dari karang.

Bulu babi merupakan pengendali populasi mikroalga. Keberadaannya di suatu ekosistem tidak lepas dari faktor fisika kimia pada lingkungan tersebut meskipun tidak berpengaruh secara langsung (Setyawan dkk., 2014). Ukuran diameter cangkang bulu babi dapat mencapai 163 mm dan berat mencapai 200 gram (Radjab, 2001 dalam Irianto dkk., 2016). Peran penting bulu babi dapat dilihat dari segi ekologis maupun ekonomis. Peran bulu bali dari segi ekologis yaitu sebagai pengontrol pertumbuhan populasi alga yang berada diperairan (Erlyta, 2015 dalam Olii dan Khair, 2017). Sementara itu, peran dalam segi ekonomis yaitu telurnya dapat dijadikan sebagai bahan makanan. Bulu babi juga bisa dijadikan sebagai indikator pencemar lingkungan.

Soualili et al., (2008). Ayeni et al. (2010) dan Chakrabortty and Paratkar (2006) dalam Rumahlatu (2012) mengatakan bahwa bulu babi ini dapat dijadikan sebagai bioindikator logam berat di perairan karena organisme ini memenuhi beberapa kriteria sebagai organisme yang 
bisa dijadikan bioindikator antara lain toleran terhadap polutan, dominan dalam populasi, dapat disampling pada semua musim, dan mudah dipelihara pada kondisi di laboratorium. Dan Bahkan dalam uji biologis embrio bulu babi dijadikan sebagai bioindikator kualitas air dan pemantauan lingkungan (Dinnel, 1994 dalam Alamrie dkk., 2013).

Suryanti dan A'in (2013) dalam Arthaz dkk., (2015) menyatakan bahwa jika di suatu ekosistem terumbu karang terdapat bulu babi terutama jenis Diadema setosum, kelimpahan dari populasi spesies tersebut penting untuk terumbu karang sebagai penyeimbang. Dikarenakan pola makan bulu babi yang umumnya memakan alga yang terdapat pada terumbu karang. Makroalga merupakan pesaing hewan karang yang memperebutkan sumberdaya ruang (sinar matahari), dan jika tidak terdapat bulu babi akan terjadi peningkatan makroalga yang mengakibatkan tertutupnya ruang tempat hidup terumbu karang yang menyebabkan perairan tersebut menjadi eutrofik. Bulu babi jenis Diadema Setosum mempunyai nilai ekonomis (Aziz, 1993; Ratna, 2002 dalamHadinoto dkk., 2017). Gonad atau telurnya merupakan bagian tubuh yang dikonsumsi (Vimono,2007 dalam Hadinoto dkk., 2017). Sumber pangan bergizi ini dapat dimanfaatkan dari organisme ini. Bulu babi jenis Diadema setosum ini gonadnya mengandung 18 jenis asam lemak tak jenuh, termasuk omega 3 dan 6 serta 15 jenis asam amino (Afifudin et al., 2014 dalam Hadinoto dkk., 2017). Khasiat dari asam lemak omega 3 untuk mengurangi resiko terkena penyakit jantung dan menurunkan kadar koleatrol di dalam darah (Almatsir, 2006 dalam Hadinoto dkk., 2017). Asam amino pada bulu babi menjadi pemacu pertumbuhan dan kesehatan (Dincer, Cakli, Kilinc, dan Tolasa, 2010). Selain dapat dijadikan sebagai sumber pangan alternafif gonad bulu babi mengandung 28 macam asam amino, vitamin B kompleks, vitamin A, mineral, asam lemak omega-3 dan 6. Dan bagian cangkangnya memiliki potensi untuk antikanker, antitumor dan antimikroba (Aprillia et al., 2012 dalam Hadinoto dkk., 2017).

Toha (2006) dalam Padang dkk., (2019) menyatakan gonad bulu babi menghasilkan 8 asam amino esensial antara lain yaitu: (arginin, histidin, triptofan, fenilalanin, lisin, metionin, treolin dan valin), sedangkan asam amino non-esensial adalah (asparat, sistein, serin, glisin, dan glutamat). 
Bukan hanya itu, gonad bulu babi juga bisa mengobati luka bakar akibat terkena api, setrika, air panas dan juga listrik (Karmilah dan Badia, 2019). Kandungan gizi bulu babi dipengaruhi oleh jenis, habitat dan nutrisi perairan. Di perairan pantai Negeri Suli Kabupaten Maluku Tengah bulu babi jenis Diadema setosum ini terdapat nilai gizi berupa asam lemak diantaranya yaitu, asam palmitoleat, linoleat, linolenat, dan oleat (Silaban dan Srimariana, 2012).

Makanan Bulu babi jenis Diadema setosum adalah lamun dan alga, hidupnya pun berkelompok karena untuk saling melindungi diri dari ancaman musuh. Tempat hidupnya adalah di bawah garis batas surut terendah (Rumahlatu, 2012). Selain itu D. Setosum melakukan mekanisme pertahanan yang terjadi akibat stressor lingkungan. Ini dilakukan untuk memberikan respon pada lingkungan seperti perilku covering/menutup sekitar habitatnya dan perilaku harian (makan, istrahat/resting, dan berpindah) (Aziz, 1994 dalam Rumahlatu, 2012). Adapun faktor yang ditentukan untuk mengetahui kualitas gonad bulu babi yaitu dilihat dariwarnanya. Kualitas warna gonad yang baik yaitu berkisar dari warna kuning terang hingga orange merah. Namun juga bukan hanya dilihat dari warnanya, tetapi ditentukan dengan tekstur gonad (padat dan halus), rasa yang enak, dan juga massa gonad (Kadir, 2009 dalam Tupan dan Silaban,2017). Tetapi jika dilakukan pengambilan bulu babi secara terus menerus akan mengakibatkan dampak negatif terhadap menurunnya populasi tersebut (Hammer et al., 2006 dalam Uneputty dkk.,2017). Akan berakibat kematian bagi larva atau karang muda jika populasi bulu babi meningkat. Dan karang akan ditumbuhi alga yang dapat menyebabkan kematian pada karang dewasa karena tidak ada tempat bagi larva karang, hal ini terjadi jika populasi bulu babi menurun (Toha, 2006 dalam Sulistiawan, 2019).

Menurut Soleimani (2017) dalam Lestiono dkk., (2020) menyatakan bahwa pada bulu babi jenis Echinometra mathaei terdapat ekstrak etanol yang besifat sebagai anti inflamasi yang serupa dengan aspirin, aspirin tergolong dalam NSAID yang dapat bekerja sebagai anti inflamasi, antipiretik dan analgesik. Cara kerja dari aspirin dengan anti inflamasi ini adalah untuk menghambat aktivitas enzim cyclooxygenase-2 (COX-2) yang menghambat pembentukan 
prostaglandin (PG) yang menyebabkan nyeri, pembekakan, peradangan dan juga demam (Vane, 2003 dalam Lestiono dkk.,2020).

\section{Conclusion}

Berdasarkan penjelasan diatas bahwa Indonesia merupakan negara kepulauan, yang memiliki kekayaan alam, flora dan fauna yang sangat tinggi. Salah satu potensi sumberdaya perikanan yang mempunyai manfaat besar bagi kehidupan manusia adalah Bulu babi (Sea Urchin). Bulu babi merupakan organisme yang tergolong dalam kelas Echinoidea dan dapat dimanfaatkan sebagai sumber pangan bergizi. Bulu babi juga dapat dijadikan sebagai hiasan dan juga berguna dibidang kesehatan guna untuk pengobatan penyakit. Salah satu habitat bagi bulu babi adalah padang lamun. Bulu babi jenis Diadema setosum ini gonadnya mengandung 18 jenis asam lemak tak jenuh, termasuk omega 3 dan 6 serta 15 jenis asam amino. Khasiat dari asam lemak omega 3 untuk mengurangi resiko terkena penyakit jantung dan menurunkan kadar kolestrol di dalam darah.gonad bulu babi menghasilkan 8 asam amino esensial antara lain yaitu: (arginin, histidin, triptofan, fenilalanin, lisin, metionin, treolin dan valin), sedangkan asam amino non-esensial adalah (asparat, sistein, serin, glisin, dan glutamat).

\section{References}

Akerina, FO, Nurhayati, T., \& Suwandi, R. (2015). Isolasi dan Karakterisasi Senyawa Antibakteri dari Landak Laut. Jurnal Pengolahan Hasil Perikanan Indonesia , 18(1).

Alamrie, M., Lalita, J. A., \& Kaligis, E. (2013). Pengaruh Berbagai Jenis Alga Mikro pada Pertumbuhan Babi Echinometra Mathaei Pluteus Larva. Jurnal Pesisir dan Laut Tropis , 1(1), 28-33. 
Arhas, F. R., Mahdi, N., \& Kamal, S. (2018). Struktur Komunitas Dan Karakteristik Bulu Babi (Echinoidea) Di Zona Sublitoral Perairan Iboh Kecamatan Sukakarya Kota Sabang. Prosiding Biotik, 2(1).

Arthaz, C. P. (2015). Hubungan Kelimpahan Bulu Babi (Sea Urchin) Dengan Bahan Organik Substrat Dasar Perairan Di Pantai Krakal, Yogyakarta. Management of Aquatic Resources Journal, 4(3), 148-155.

Basir, N. (2014). Uji Antimitosis Ekstrak Etanol Larut dan Tidak Larut Daun n-Heksan Katuk (Sauropus androgynus L. Merr) Berdasarkan Disertasi Doktor, Universitas Islam Negeri Alauddin Makassar.

Silaban, B., \& Srimariana, E. S. (2014). Kandungan Nutrisi Dan Pemanfaatan Gonad Bulu Babi (Echinothrixs Calamaris) Dalam Pembuatan Kue Bluder. Jurnal Pengolahan Hasil Perikanan Indonesia, 16(2).

Firmandana, T. C. (2014). Kelimpahan Bulu Babi (Sea Urchin) pada Ekosistem Karang dan Lamun di Perairan Pantai Sundak, Yogyakarta. Management of Aquatic Resources Journal, 3(4), 41-50.

Hadinoto, S., Sukaryono, I. D., \& Siahay, Y. (2017). Kandungan Gizi Gonad dan Aktivitas Antibakteri Ekstrak Cangkang Bulu Babi (Diadema setosum). Jurnal Pascapanen dan Bioteknologi Kelautan dan Perikanan, 12(1), 71-78.

Irianto, A., Jahidin, J., \& Sudrajat, H. W. (2016). Kelimpahan Bulu Babi (Echinoidea) Di Intertidal Perairan Pulau Liwutongkidi Kecamatan Siompu Kabupaten Buton Selatan. Jurnal Ampibi (Almuni Pendidikan Biologi), 1(2).

Juliawan, J., Dewiyanti, I., \& Nurfadillah, N. (2017). Kelimpahan dan Pola Sebaran Bulu Babi (Echinodea) di Perairan Pulau Klah Kota Sabang. Jurnal Ilmiah Mahasiswa Kelautan Perikanan Unsyiah, 2(4). 
Karmilah, K., \& Badia, E. (2019). Pengaruh Ekstrak Gonad Laut (Diadema Setosum) sebagai Penyembuh Sumur Bakar pada Kelinci (Oryctolagus cuniculus). Jendela Kesehatan: Jurnal Kesehatan , 65-76.

Laning, T. H., Yusup, D. S., \& Wiryatno, J. (2014). Sebaran Bulu Babi (Echinoidea) Di Kawasan Padang Lamun Pantai Merta Segara, Sanur-Bali. Jurnal Biologi Udayana, 18(2).

Lestiono, L., \& Kresnamurti, A. (2020). Aktivitas Analgesik Ekstrak Etanol Bulu Babi (Echinometra Mathaei) Pada Mencit Putih Jantan. Journal Of Herbal, Clinical And Pharmaceutical Science (Herclips), 1(02), 7-12.

Lubis, S. A., Purnama, A. A., \& Yolanda, R. (2017). Spesies Bulu Babi (Echinoidea) Di Perairan Pulau Panjang Kabupaten Bangka Tengah Provinsi Bangka Belitung. Jurnal IImiah Mahasiswa FKIP Prodi Biologi, 3(1)

Miala, I., Pratomo, A., \& Irawan, H. (2015). Hubungan Antara Bulu Babi, Makroalgae Dan Karang Di Perairan Daerah Pulau Pucung. Repository UMRAH.

Nane, L. (2019a). Efisiensi Mesin Teknologi Sapurata Dalam Mengoptimalisasi Produksi Inovasi Pangan Kukure Di Pulau Barrang Lompo, Makassar. https://doi.org/10.31230/osf.io/q8spg

Nane, L. (2019b). Impact of overfishing on density and test-diameter size of the sea urchin Tripneustes gratilla at Wakatobi Archipelago, south-eastern Sulawesi, Indonesia. BioRxiv, 727271. https://www.biorxiv.org/content/10.1101/727271v1

Nane, L. (2019c). Sea Urchin Sustainability Studies Based on Dimension Biology, Ecology and Technology at Around of Tolandono Island and Sawa Island at Wakatobi Conservation Area. https://doi.org/10.31230/osf.io/4whz6

Nane, L. (2019d). Studi Keberlanjutan Perikanan Landak Laut Berdasarkan Dimensi Biologi, Ekologi Dan Teknologi Di Sekitar Pulau Tolandono Dan Pulausawa Kawasan Konservasiwakatobi [Skripsi, Universitas Hasanuddin]. Https://Marxiv.Org/9zdvr/

Nane, L., Baruadi, A. S. R., \& Mardin, H. (2020). The density of the blue-black urchin Echinotrix diadema (Linnaeus, 1758) in TominiBay, Indonesia. Tomini Journal of Aquatic Science, 1(1), 16-21. https://doi.org/10.37905/tjas.v1i1.5939 
Nasrullah, R., Sari, W., \& Mellisa, S. (2018). Tingkat Kematangan Gonad Bulu Babi (Tripneustes gratilla) di Pantai Ahmad Rhangmayang Kecamatan Mesjid Raya Kabupaten Aceh Besar. Jurnal IImiah Mahasiswa Kelautan Perikanan Unsyiah, 3(1).

Padang, A., Nurlina, N., Tuasikal, T., \& Subiyanto, R. (2019). Kandungan Gizi Bulu Babi (Echinoidea). Agrikan: Jurnal Agribisnis Perikanan, 12(2), 220-227.

Prasetyo, E., Zaida, A. A., Wulan, I. N., Wulandari, R., Santiati, E., \& Prakoso, C. N. Y. (2019). Kekayaan Jenis Bulu Babi (Sea Urchin) di Kawasan Perairan Pantai Gunung Kidul, Yogyakarta. Biospecies, 12(1), 33-39.

Purwandatama, R. W., \& Ain, C. (2013). Kelimpahan Bulu Babi (Sea Urchin) pada Karang Massive dan Branching di Daerah Rataan dan Tubir di Legon Boyo, Pulau Karimunjawa, Taman Nasional Karimunjawa. Management of Aquatic Resources Journal, 3(1), 17-26.

Rumahlatu, D. (2012). Aktivitas Makan dan Pertumbuhan Bulu Babi Deadema setosum Akibat Paparan Logam Berat Kadmium (Feeding Activity and Growth Sea Urchins Deadema setosum Due to Heavy Metal Cadmium Exposure). ILMU KELAUTAN: Indonesian Journal of Marine Sciences, 17(4), 183-189.

Rumahlatu, D. (2012). Respons perilaku bulu babi Deadema setosum terhadap logam berat kadmium. Bumi Lestari Journal of Environment, 12(1), 45-54.

Setyawan, B., Sulardiono, B., \& Purnomo, P. W. (2014). Kelimpahan Bulu Babi (Sea Urchin) pada

Ekosistem Terumbu Karang dan Ekosistem Padang Lamun di Pulau Panjang, Jepara. Management of Aquatic Resources Journal, 3(2), 74-81.

Silvina, S. (2017). Keanekaragaman echinodermata di zona intertidal Gili Trawangan Kabupaten Lombok Utara (Doctoral dissertation, Universitas Islam Negeri Mataram).

Sulistiawan, R., Solichin, A., \& Rahman, A. (2019). Hubungan Kerapatan Lamun Dengan Kelimpahan Bulu Babi (Echinoidea) Di Pantai Pancuran Taman Nasional Karimunjawa, Jepara The Correlation of Seagrass Density with Abundance of Sea Urchins (Echinoidea) in Pancuran 
Beach Karimunjawa National Park, Jepara. Management of Aquatic Resources Journal, 8(1), 28-36.

Tupan, J., \& br Silaban, B. (2017). Karakteristik Fisik-Kimia Bulu babi Diadema setosum dari beberapa Perairan Pulau Ambon. Triton, 13(2), 71-78.

Uneputty, P. A., Pattikawa, J. A., \& Rijoly, F. (2017). Status Populasi Bulu Babi Tripneustes gratilla di Perairan Desa Liang, Pulau Ambon. Omni-Akuatika, 12(3).

Wulandewi, N. L. E., Subagio, J. N. J. N., \& Wiryatno, J. (2015). Jenis dan Densitas Bulu Babi (Echinoidea) Di Kawasan Pantai Sanur dan Serangan Denpasar-Bali. Simbiosis, 3(1).

Yudasmara, G. A. (2013). Keanekaragaman Dan Dominansi Komunitas Bulu Babi (Echinoidea) Di Perairan Pulau Menjangan Kawasan Taman Nasional Bali Barat. JST (Jurnal Sains dan Teknologi), 2(2).

Zakaria, I. J. (2013). Komunitas Bulu Babi (Echonoidea) di Pulau Cingkuak, Pulau Sikuai dan Pulau Setan Sumatera Barat. Prosiding Semirata 2013, 1(1). 